\title{
PARTS, Wholes, AND PART-Whole Relations: THE PROSPECTS OF MEREOTOPOLOGY
}

\author{
Achille C. Varzi \\ Department of Philosophy, Columbia University (New York) \\ (Published in Data and Knowledge Engineering 20 (1996), 259-286.)
}

\section{INTRODUCTION}

This is a brief overview of formal theories concerned with the study of the notions of (and the relations between) parts and wholes. The guiding idea is that we can distinguish between a theory of parthood (mereology) and a theory of wholeness (holology, which is essentially afforded by topology), and the main question examined is how these two theories can be combined to obtain a unified theory of parts and wholes.

We examine various non-equivalent ways of pursuing this task, mainly with reference to its relevance to spatio-temporal reasoning. In particular, three main strategies are compared: (i) mereology and topology as two independent (though mutually related) theories; (ii) mereology as a general theory subsuming topology; (iii) topology as a general theory subsuming mereology. This is done in Sections 4 through 6 . We also consider some more speculative strategies and directions for further research. First, however, we begin with some preliminary outline of mereology (Section 2) and of its natural bond with topology (Section 3).

\section{MEREOLOGY: A REVIEW}

The analysis of parthood relations (mereology, from the Greek $\mu \varepsilon \rho \varsigma_{\text {, }}$ 'part') has for a long time been a major focus of philosophical investigation, beginning as early as with atomists and continuing throughout the writings of ancient and medieval ontologists. It made its way into contemporary philosophy through the work of Brentano and of his pupils, most notably Husserl's third Logical Investigation, and it has been subjected to formal treatment from the very first decades of this century. Indeed, formal mereological theories have often been associated with a nominalistic 
stand-as an ontologically parsimonious alternative to set theory, dispensing with abstract entities or (more precisely) treating all objects of quantification as individuals. This is true of the two main theories set forth in the early years, i.e., the system of Leś niewski [38] and that of Leonard and Goodman [37] (emblematically called Calculus of Individuals). However, there is no necessary between mereology and the philosophical position of nominalism. As a formal theory, mereology is simply an attempt to set out the general principles underlying the relationships between a whole and its constituent parts, just like set theory is an attempt to set out the principles underlying the relationships between a class and its constituent members. Unlike set theory, mereology is not committed to the existence of abstract entities. (The whole can be just as concrete as the parts.) But this carries no nominalistic commitment either. Mereology can be credited a fundamental role whether or not we take the entire universe to be describable exclusively in terms of parthood relationshipsand its recent revival in connection with knowledge representation and conceptual analysis in AI research bears witness to this prospect.

Historically, after Husserl's original formulation, formal mereology grew out essentially of the two theories mentioned above. In fact, although they came in different logical guises, these theories turn out to be essentially equivalent and provide a common basis for most subsequent developments. They are rather strong theories, though - that is, they incorporate principles that are neither obvious nor uncontroversial for the purpose of explaining the ordinary notions of part and whole. For our purposes, it may be more convenient to neglect the chronological order and begin with some more basic_albeit very sketchy—characterizations. (For a systematic presentation of formal mereologies, see [22,60,61]. On its historical background, see $[11,31]$. For a wealth of annotated references, mostly in the philosophical tradition, see $[63,64]$.)

Barring for the moment the complications arising from the consideration of intensional factors (such as time, modalities, and counterfactuals), we may view a mereological theory as a first-order theory characterized first of all by some basic "lexical" principles-principles setting out the basic semantic traits of the word 'part' (and of kindred notions). In particular, virtually every theory agrees on treating parthood as a partial ordering - a reflexive, antisymmetric, transitive relation. We may call such a characterization Ground Mereology, regarding it as the common basis of all part-whole theories.

DEFINITION 1. Ground Mereology [M] is the theory defined by the following proper axioms for the Parthood predicate, 'P': 


$$
\begin{array}{ll}
\text { (P1) } & \text { Р } x x \\
\text { (P2) } & \text { Р } x y \wedge \mathrm{P} y x \rightarrow x=y ; \\
\text { (P3) } & \text { Р } x y \wedge \mathrm{P} y z \rightarrow \mathrm{P} x z .
\end{array}
$$

(Here and in the following we assume a standard first-order language with identity supplied with a distinguished binary predicate constant, 'P', to be interpreted as the (possibly improper) parthood relation. The underlying logic is understood to be a standard first-order calculus with identity.)

To be sure, this characterization is not entirely uncontroversial. For instance, since [57] several authors have had misgivings about the transitivity of ' $\mathrm{P}$ ' (the handle is part of the door, the door is part of the house, but the handle is not part of the house; see also [19,27, 31, 45, 80] inter alia). However, this objection typically involves a departure from the broadest possible notion of parthood that $\mathbf{M}$ is meant to capture, as the general intended interpretation of ' $\mathrm{P}$ ' is narrowed by additional conditions (e.g., by requiring that parts make a direct contribution to the functioning of the whole). The objection may therefore be disregarded as long as we remain at a purely extensional and sufficiently general level of analysis. (The intended nontransitivity can always be recovered with the help of explicit specifications: A handle is, say, a functional part of a door, the door is a functional part of the house, but the handle is not a functional part of the house. More generally, where ' $\phi$ ' is any formula in the language, the implication:

$$
(\mathrm{P} x y \wedge \phi[x, y]) \wedge(\mathrm{P} y z \wedge \phi[y, z]) \rightarrow(\mathrm{P} x z \wedge \phi[x, z])
$$

may well fail to be an $\mathbf{M}$-theorem.)

Given (P1)-(P3), a number of additional mereological relations can be introduced by exploiting the intended interpretation of ' $\mathrm{P}$ '. In particular, $\mathbf{M}$ supports the following useful definitions (see Figure 1):

$$
\begin{array}{lll}
\mathrm{PP} x y & =_{\mathrm{df}} & \mathrm{P} x y \wedge \neg \mathrm{P} y x \\
\mathrm{O} x y & =_{\mathrm{df}} & \exists z(\mathrm{P} z x \wedge \mathrm{P} z y) \\
\mathrm{U} x y & =_{\mathrm{df}} & \exists z(\mathrm{P} x z \wedge \mathrm{P} y z) \\
\mathrm{OX} x y & =_{\mathrm{df}} & \mathrm{O} x y \wedge \neg \mathrm{P} x y \\
\mathrm{UX} x y & =_{\mathrm{df}} & \mathrm{U} x y \wedge \neg \mathrm{P} y x \\
\mathrm{PO} x y & =_{\mathrm{df}} & \mathrm{OX} x y \wedge \mathrm{OX} y x \\
\mathrm{PU} x y & =_{\mathrm{df}} & \mathrm{UX} x y \wedge \mathrm{UX} y x
\end{array}
$$

$$
\begin{aligned}
& \text { (Proper Part) } \\
& \text { (Overlap) } \\
& \text { (Underlap) } \\
& \text { (Over-Crossing) } \\
& \text { (Under-Crossing) } \\
& \text { (Proper Overlap) } \\
& \text { (Proper Underlap) }
\end{aligned}
$$

It is immediately verified that 'PP' defines a strict partial ordering whereas ' $\mathrm{O}$ ' and ' $U$ ' are symmetric relations satisfying the following: 


$$
\begin{aligned}
& \mathbf{M}+\mathrm{P} x y \rightarrow \forall z(\mathrm{O} z x \rightarrow \mathrm{O} z y) \\
& \mathbf{M}+\mathrm{P} x y \rightarrow \forall z(\mathrm{U} y z \rightarrow \mathrm{U} x z)
\end{aligned}
$$

(The converses do not hold, though they will hold in the strengthenings of $\mathbf{M}$ considered below.) We can also define identity, as per the following immediate consequence of (P2):

$$
\mathbf{M}+x=y \leftrightarrow \mathrm{P} x y \wedge \mathrm{P} y x .
$$

In this case, the theory can be formulated in a pure first-order language (without identity), as long as the axioms for identity are explicitly added to (P1)-(P3).

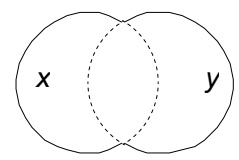

Oxy $\mid$ Oyx

(Uxy) (Uyx)

OXxy OXyx

$(\mathrm{UX} x y) \quad(\mathrm{UX} y x)$

POxy POyx

$(\mathrm{PU} x y) \quad(\mathrm{PU} y x)$

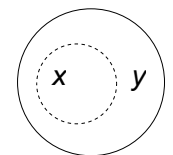

Oxy $\quad$ Oyx

Uxy Uyx

Pxy OXyx

$\mathrm{PP} x \mathrm{P}$

$\mathrm{UX} x y$

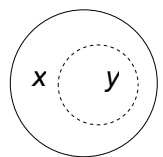

\begin{tabular}{r|l} 
Oxy & Oyx \\
Uxy & Uyx \\
OXxy & Pyx \\
& PPyx \\
& UXyx
\end{tabular}

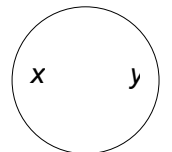

Oxy Oyx

Uxy Uyx

Pxy Pyx

$x=y \quad y=x$

Figure 1: The four basic patterns of mereological relationship. The leftmost pattern in turn corresponds to two distinct situations (validating or falsifying the clauses in parenthesis) depending on whether or not there is a larger $z$ including both $x$ and $y$.

The ground theory $\mathbf{M}$ may be viewed as embodying the "lexical" basis of a mereological theory. Not just any partial ordering will qualify as a part-whole relation, though, and establishing what further principles should be added to (P1)-(P3) is precisely the question a good mereological theory is meant to account for. These further principles are inevitably more substantial and to some extent stipulative, and over the years various non-equivalent developments have been put forward. A thorough discussion can be found in [22] and [60]. Here we only mention some systems which are particularly relevant for the following sections, all of which played a significant role in traditional philosophical discussion as well as in recent developments in AI. 
Generally speaking, these systems may be viewed as resulting from $\mathbf{M}$ by adding principles asserting the (conditional) existence of certain mereological items given the existence of other items. Thus, the first system embodies the idea that whenever an object is not part of another, there is a third object which is part of the first but not of the second. The second system embodies the intuition that the domain be closed - on certain conditions - under the operations of mereological sum, product, and difference. And the third system-corresponding to the most common system in the literature-is obtained by strengthening this intuition so as to allow for closure under infinitary operations.

DEFINITION 2. The theory of Extensional Mereology [EM] is the extension of $\mathbf{M}$ obtained by adding the "Supplementation Axiom":

(P4) $\quad \neg \mathrm{P} x y \rightarrow \exists z(\mathrm{P} z x \wedge \neg \mathrm{O} z y)$.

(P4) is sometimes called "strong" supplementation, to distinguish it from the weaker supplementation principle to the effect that if an individual has a proper part, it has more than one. It is easily seen that this is implied by (P4):

$$
\mathbf{E M} \vdash \mathrm{PP} x y \rightarrow \exists z(\mathrm{PP} z y \wedge \neg \mathrm{O} z x)
$$

although the converse does not hold: a countermodel is given by two objects which have exactly the same proper parts. In fact, the exclusion of such models is what justifies the term "extensionality" in the present context: besides (9) we have

$$
\mathbf{E M}+\exists z \mathrm{PP} z x \wedge \forall z(\mathrm{PP} z x \rightarrow \mathrm{PP} z y) \rightarrow \mathrm{P} x y,
$$

and therefore

$$
\mathbf{E M}+\exists z \mathrm{PP} z x \wedge \forall z(\mathrm{PP} z x \leftrightarrow \mathrm{PP} z y) \rightarrow x=y,
$$

i.e., no two distinct objects can share the same proper parts. Here (14) is the mereological counterpart of the familiar set-theoretic extensionality principle, as it reflects the view that an object is exhaustively defined by its constituent parts (just as a class is exhaustively defined by its constituent elements). This principle obviously fails in intensional contexts (see again [60] for discussion and overview), but it has been assumed in almost every tenseless, non-modal mereological theory put forward in the literature-except for some of the mereotopological systems which incorporate the topological option discussed below in Section 5 . 
PARTS, WHOLES, AND PART-WHOLE RELATIONS

DEFINITION 3. The theory of Closed (Extensional) Mereology $[\mathbf{C}(\mathbf{E}) \mathbf{M}]$ is the extension of $(\mathbf{E}) \mathbf{M}$ obtained by adding the following axioms:

(P5) $\quad \mathrm{U} x y \rightarrow \exists z \forall w(\mathrm{O} w z \leftrightarrow(\mathrm{O} w x \vee \mathrm{O} w y))$,

(P6) $\quad \mathrm{O} x y \rightarrow \exists z \forall w(\mathrm{P} w z \leftrightarrow(\mathrm{P} w x \wedge \mathrm{P} w y))$,

(P7) $\quad \exists z(\mathrm{P} z x \wedge \neg \mathrm{O} z y) \rightarrow \exists z \forall w(\mathrm{P} w z \leftrightarrow(\mathrm{P} w x \wedge \neg \mathrm{O} w y))$.

Note that in the presence of (P4), the entities whose conditional existence is asserted by (P5)-(P7) are unique by (14). Thus, if the language has a description operator ' ', CEM supports the following definitions:

$$
\begin{aligned}
& x+y==_{\mathrm{df}} \quad z \forall \forall w(\mathrm{O} w z \leftrightarrow(\mathrm{O} w x \vee \mathrm{O} w y)) \\
& \text { (sum) } \\
& x \times y==_{\mathrm{df}} \quad z \forall \forall w(\mathrm{P} w z \leftrightarrow(\mathrm{P} w x \wedge \mathrm{P} w y)) \\
& x-y==_{\mathrm{df}} \quad z \forall \forall w(\mathrm{P} w z \leftrightarrow(\mathrm{P} w x \wedge \neg \mathrm{O} w y)) \\
& \text { (difference) }
\end{aligned}
$$

(Here ' 1 ' may be assumed as part of the logical vocabulary or defined contextually $\grave{a}$ la Russell [57]:

$$
\psi[1 x \phi]=_{\mathrm{df}} \exists y(\forall x(\phi \leftrightarrow x=y) \wedge \psi[y])
$$

The two options are not equivalent, but I shall avoid unnecessary complications [62].) (P5)-(P7) can then be rephrased more perspicuously as:

$$
\begin{aligned}
& \text { (P5') } \quad \mathrm{U} x y \rightarrow \exists z(z=x+y) \\
& \text { (P6') } \mathrm{O} x y \rightarrow \exists z(z=x \times y) \\
& \text { (P7') } \quad \exists z(\mathrm{P} z x \wedge \neg \mathrm{O} z y) \rightarrow \exists z(z=x-y) .
\end{aligned}
$$

$\mathbf{C}(\mathbf{E}) \mathbf{M}$ is somewhat more controversial than the weaker $(\mathbf{E}) \mathbf{M}$, since it involves an increase in the number of entities admitted in a mereological domain. (One could argue that the increase is only apparent: for instance, a sum is, in a sense, nothing over and above the things that compose it [39]; likewise, a product adds nothing. But formally there is no question that a $\mathbf{C}(\mathbf{E}) \mathbf{M}$ model is more densely populated than an (E)M model.) On the other hand, the algebraic neatness allowed by (P5) is not to be undervalued, and it makes $\mathbf{C}(\mathbf{E}) \mathbf{M}$ rather attractive particularly if one's purpose is to do without set theory.

In many versions, $\mathbf{C}(\mathbf{E}) \mathbf{M}$ also involves an axiom to the effect that the universe is bounded above, i.e., there is something of which everything is part:

$$
\exists z \forall x(\mathrm{P} x z) .
$$

In the presence of extensionality, such an object is of course unique, and this makes 
it possible in CEM to define an operator associating all (non-universal) objects with their complement.

$$
\begin{aligned}
& U={ }_{\mathrm{df}} 1 z \forall x(\mathrm{P} x z) \\
& \sim x={ }_{\mathrm{df}} U-x
\end{aligned}
$$

(universe)

(complement)

This makes the algebraic structure of $\mathbf{C E M}$ even neater, since it guarantees that any two objects have a sum. (The presence of (19) trivializes the underlap relation ' $U$ '.) Sometimes, however, this has been disputed on intuitive grounds, the standard objection being that unrestricted (P5) may have counter-intuitive instances when $x$ and $y$ are scattered or otherwise ill-assorted entities, such as two distinct cats, or this printed page and the topmost stone of the Empire State Building (see the classical criticism in [42]). We shall come back to this below. On the other hand, note that only a few authors have gone so far as to postulate the existence of a null individual which is part of everything:

$$
\text { (22) } \exists z \forall x(\mathrm{P} z x)
$$

(An exception is [43]; see also $[9,10]$ for a theory with several null individuals.) For this reason, the existence of a product or a difference is not always guaranteed, and (P6)-(P7) need be in conditional form. Likewise, the complement operator will not be defined for $U$.

We can also add infinitary closure conditions, allowing for instance for the possibility of summing arbitrary non-empty sets of objects (which in turn implies the possibility of making the product of arbitrary sets of overlapping objects: the product of all members of a class $A$ is just the sum of all those things that are part of every member of A). This is not immediately obvious if we want to avoid commitment to classes and stick to an ordinary first-order theory. As a matter of fact fact, in some classical systems such as [68] or [37], the formulation of these conditions does involve explicit reference to classes. On the other hand, we can avoid such reference by relying on axiom schemes that involve only predicates or open formulas. Specifically, we can say that for every satisfied property or condition $\phi$ there is an entity consisting of all those things that satisfy $\phi$. Since an ordinary first-order language has a denumerable supply of predicates or formulas, at most denumerably many classes (in any given domain) can be specified in this way. But this limitation is of course negligible if we are inclined to deny that classes exist except as nomina. We thus arrive at what has come to be known as Classical or General Mereology. 
PARTS, WHOLES, AND PART-WHOLE RELATIONS

DEFINITION4. The theory of General (Extensional) Mereology $[\mathbf{G}(\mathbf{E}) \mathbf{M}]$ is the extension of (E)M obtained by adding the "Fusion Axiom":

(P8) $\quad \exists x \phi \rightarrow \exists z \forall y(\mathrm{O} y z \leftrightarrow \exists x(\phi \wedge \mathrm{O} y x))$.

It is immediately verified that $\mathbf{G}(\mathbf{E}) \mathbf{M}$ is actually an extension of $\mathbf{C}(\mathbf{E}) \mathbf{M}$, i.e., (P5)-(P7) (and (14)) follow from (P8). Moreover, if we have extensionality, then again we have that at most one entity can satisfy the consequent of (P8). Thus, in GEM we can define general sums and products:

$$
\begin{aligned}
& \sigma x \phi==_{\mathrm{df}} \mathrm{l} z \forall y(\mathrm{O} y z \leftrightarrow \exists x(\phi \wedge \mathrm{O} y x)) \\
& \pi x \phi=_{\mathrm{df}} \sigma z \forall x(\phi \rightarrow \mathrm{P} z x)
\end{aligned}
$$

(P8) then becomes

$$
\text { (P8') } \exists x \phi \rightarrow \exists z(z=\sigma x \phi)
$$

which implies

(25) $\exists x \phi \wedge \exists y \forall x(\phi \rightarrow \mathrm{P} y x) \rightarrow \exists z(z=\pi x \phi)$

and we have the following definitional equivalences (when defined):

(26) $\quad$ GEM $+x+y=\sigma z(\mathrm{P} z x \vee \mathrm{P} z y)$

(27) $\quad$ GEM $+x \times y=\sigma z(\mathrm{P} z x \wedge \mathrm{P} z y)$

(28) $\quad$ GEM $+x-y=\sigma z(\mathrm{P} z x \wedge \neg \mathrm{O} z y)$

(29) $\mathbf{G E M}+\sim x=\sigma z(\neg \mathrm{O} z x)$

(30) $\mathbf{G E M}+U=\sigma z(\mathrm{P} z z)$

(Compare these with the standard definitions of the corresponding set-theoretic notions, with $\lambda$-abstraction in place of fusion.) Moreover, it should be noted that GEM is slightly redundant, in that (P4) can be replaced by the weaker supplementation principle mentioned in (12). We have in fact

$$
\mathbf{M}+(\mathrm{PP} x y \rightarrow \exists z(\mathrm{PP} z y \wedge \neg \mathrm{O} z x)) \rightarrow(\mathrm{P} 8) \rightarrow(\mathrm{P} 4) .
$$

This gives us the full strength of GEM. Various other equivalent formulations are also available, using different primitives and/or different sets of axioms. In the following, however, we shall stick to the above formulation for ease of comparison.

Before concluding, we consider the possibility of further strengthening a mereological theory by pronouncing on the question of whether or not there are atoms, and whether everything is made up of atoms. 
PARTS, WHOLES, AND PART-WHOLE RELATIONS

DEFINITION 7. Let $\mathbf{X}$ be any mereological theory. The Atomistic variant of $\mathbf{X}$ [labelled $\mathbf{A X}$ ] is the extension of $\mathbf{X}$ obtained by adding the axiom:

(P9) $\quad \forall x \exists y(\mathrm{P} y x \wedge \neg \exists z \mathrm{PP} z y)$.

The Atomless variant of $\mathbf{X}$ [labelled $\overline{\mathbf{A}} \mathbf{X}$ ] is the extension of $\mathbf{X}$ obtained by adding the axiom:

(P10) $\forall x \exists y \mathrm{PP} y x$.

Obviously, (P9) and (P10) are mutually inconsistent. On the other hand, it is easy to verify that any mereological theory considered here (M, EM, CM, CEM, GM,

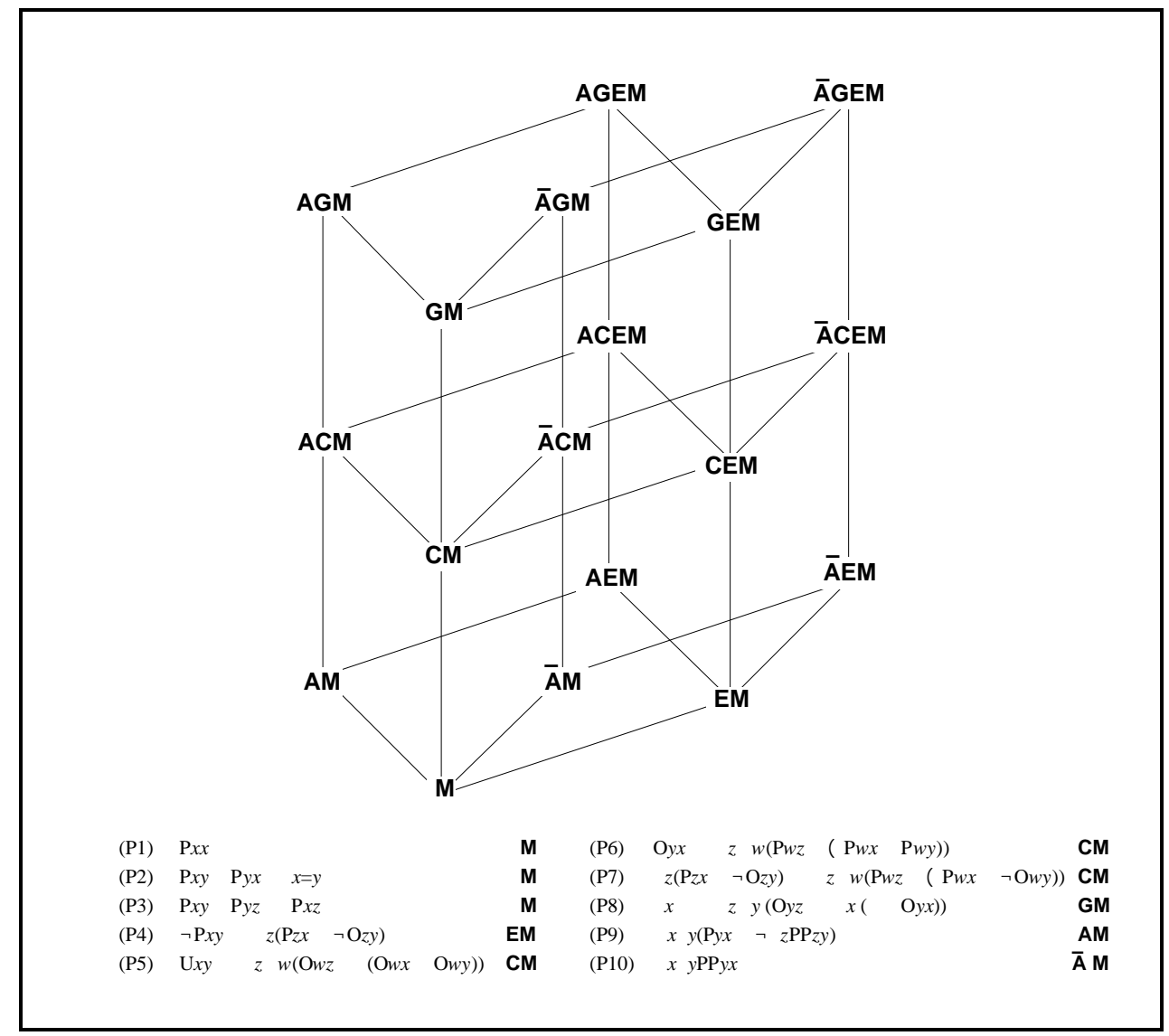

Figure 2: Hess diagram of the basic mereological systems (the inclusion relation goes uphill); in the listing, the characteristic axioms are matched with the lowest theory in which they appear. 


\section{PARTS, WHOLES, AND PART-WHOLE RELATIONS}

GEM) is compatible with either position, and can therefore be made into an atomic or an atomless system as the case may be. Indeed, any finite model of GEM (and $a$ fortiori of its weaker subtheories) must be atomistic, so an atomless model must have infinite cardinality. Moreover, atomistic mereologies admit of significant simplifications in the remaining axioms. For instance, AEM can be simplified by replacing (P4) and (P9) by the following:

$$
\forall z(\neg \exists w \mathrm{PP} w z \wedge \mathrm{P} z x \rightarrow \mathrm{P} z y) \rightarrow \mathrm{P} x y,
$$

whence it is apparent that an atomistic extensional mereology is strongly extensional: things built up from the same atoms are identical. For more discussion on this and related aspects, see [22] and references therein.

PROPOSITION 1 (Tarski [69]). Every model of (A)GEM is isomorphic to an (atomic) complete quasi-Boolean algebra $(=$ Boolean algebra with the zero element removed). A model of $\overline{\mathbf{A}} \mathbf{G E M}$ is given by a complete quasi-Boolean algebra on the set of regular open subsets of a Euclidean Space.

\section{THE NEED FOR TOPOLOGY}

We said that mereology can be credited a fundamental role regardless of whether we take the entire universe to be describable in mereological terms. Even so, the question arises of how far we can go with it-how much of the universe can be grasped by means of purely mereological notions. And one of the most interesting developments of recent years stems precisely from a partly negative answer to this question. A purely mereological outlook is just too tight, and one need go beyond the bounds of a pure theory of parthood to come out with a true theory of parts and wholes. That is, mereological reasoning by itself cannot do justice to the notion of a whole (a one-piece, self-connected whole, such as a stone or a whistle, as opposed to a scattered entity made up of several disconnected parts, such as a broken glass, an archipelago, or the sum of two distinct cats). Parthood is a relational concept, wholeness a global property, and the latter just runs afoul of the former.

This is apparent if we consider GEM. For every whole there is a set of (possibly potential) parts; for every specifiable set of parts (i.e., arbitrary objects) there is in principle a complete whole, viz. its mereological sum, or fusion. But there is no way, within the theory, to draw a distinction between "good" and "bad" wholes; there is no way to tell an integral whole from a scattered sum of disparate 
entities by reasoning exclusively in terms of parthood. Nor is this a shortcoming of the compositional strength of GEM (or of $\mathbf{C E M}$, for that matter), i.e., of the lack of significant restrictions on the generating power of the sum and fusion operators. The point is precisely that it is not possible, mereologically, to single out the relevant restrictions. (In CEM the existence of a sum $x+y$ is conditional to the existence of an object $z$ containing both $x$ and $y$. But nothing says what properties this object must have.) In fact, one might even argue that it is not a task of mereology to specify which wholes are to count as "natural", just as ascertaining which sentences are actually "true" is not a task of semantics but an empirical issue. The real source of difficulty is different. It is that the question of what constitutes a natural whole cannot even be formulated in mereological terms. As soon as we allow for the possibility of scattered entities we lose every chance to discriminate them from integral wholes; yet we cannot just keep the latter without some means of discriminating them from the former.

As suggested elsewhere [72] (see also [73,13]), Whitehead's early attempts to characterize his ontology of events provide a good exemplification of this mereological dilemma. Whitehead's systems $[77,78]$ do not satisfy (P5) (they are therefore weaker than $\mathbf{C E M}$ ), for the intended domain is not to include scattered wholes. For Whitehead, a necessary condition for two events to have a sum is that they be at least "joined" to each other, i.e., connected (be they discrete or not). This is defined thus:

$$
\mathrm{J} x y={ }_{\mathrm{df}} \exists z(\mathrm{O} z x \wedge \mathrm{O} z y \wedge \forall w(\mathrm{P} w z \rightarrow \mathrm{O} w x \vee \mathrm{O} w y))
$$

But it is immediately verified that this definition falls short of capturing the intended relation. For nothing guarantees that the item $z$ overlaying two "joined" items $x$ and $y$ be itself a one-piece entity. (Think of two separate discs overlapping the scattered sum of their facing halves.)

These considerations apply mutatis mutandis to other attempts to subsume topological connectedness within a bare mereological framework (see e.g. [8, 46]). Nor is this exclusively an ontological concern. These limits show up in any attempt to account for very basic spatio-temporal relations, such as the relationship between an object and its surface, or the relation of continuity between two successive events, or the relation of something being inside or around something else. All of these - and many others indeed — are relations that any theory concerned with spatio-temporal entities should supply and which cannot, however, be defined directly in terms of plain mereological primitives. 
It is here that topology comes into the picture. In recent literature, this need to overcome the bounds of mereology has been handled in various ways, but most proposals stem from a common intuition: overlooking the microscopic discontinuity of matter, the question of what characterizes objects that are all of a piece requires topological analysis. Regardless of what specific principles we assume, a mereological account must be supplemented with a topological machinery of some sort.

To facilitate comparisons, let us expand our language by adding a second distinguished predicate constant, ' $\mathrm{C}$ ', to be understood intuitively as the relation of topological connection (the "join" relation that Whitehead was seeking to capture with (33)). The question of how mereology can actually be expanded to a richer part-whole theory may then be addressed by investigating how a P-based mereological system of the sort outlined above can be made to interact with a C-based topological system. Again, we may distinguish for this purpose "lexical" from substantial postulates for ' $\mathrm{C}$ ', regarding the former as embodying a set of minimal prerequisites that any system purporting to explicate the meaning of the concept of 'connection' must satisfy. Usually, these include the twofold requirement that ' $\mathrm{C}$ ' be at least reflexive and symmetric, and that it be monotonic with respect to ' $\mathrm{P}$ ' (whatever is connected to a part is also connected to the whole). We shall call this minimal theory Ground Topology, in analogy with the terminology of Definition 1.

DEFINITION 5. Ground Topology [ $[\mathbf{T}]$ is the theory defined by the following proper axioms for the Connection predicate, ' $\mathrm{C}$ ':

(C1) C $\mathrm{Cx}$;

(C2) $\mathrm{C} x y \rightarrow \mathrm{C} y x$.

(C3) $\quad \mathrm{P} x y \rightarrow \forall z(\mathrm{C} z x \rightarrow \mathrm{C} z y)$.

It is understood that ' $\mathrm{C}$ ' may on some interpretations collapse directly onto ' $\mathrm{O}$ '. However, on the intended interpretation ' $\mathrm{C}$ ' may also apply in case of external connection - connection without sharing of parts. Hence ' $\mathrm{O}$ ' will generally be a proper subrelation of ' $\mathrm{C}$ ', which means that the variety of distinct relations available in the extended language is potentially much richer. In particular, we may set:

$$
\begin{aligned}
& \mathrm{EC} x y==_{\mathrm{df}} \mathrm{C} x y \wedge \neg \mathrm{O} x y \\
& \mathrm{TP} x y==_{\mathrm{df}} \mathrm{P} x y \wedge \exists z(\mathrm{EC} z x \wedge \mathrm{EC} z y) \quad \text { (Tangential Part) } \\
& \mathrm{IP} x y==_{\mathrm{df}} \mathrm{P} x y \wedge \neg \mathrm{TP} x y
\end{aligned}
$$

As the patterns of Figure 3 indicate, these relations are distinct from the purely 
mereological relations introduced in (2)-(8). (Tangential or internal proper parts, TPP and IPP, are defined in the obvious way.)

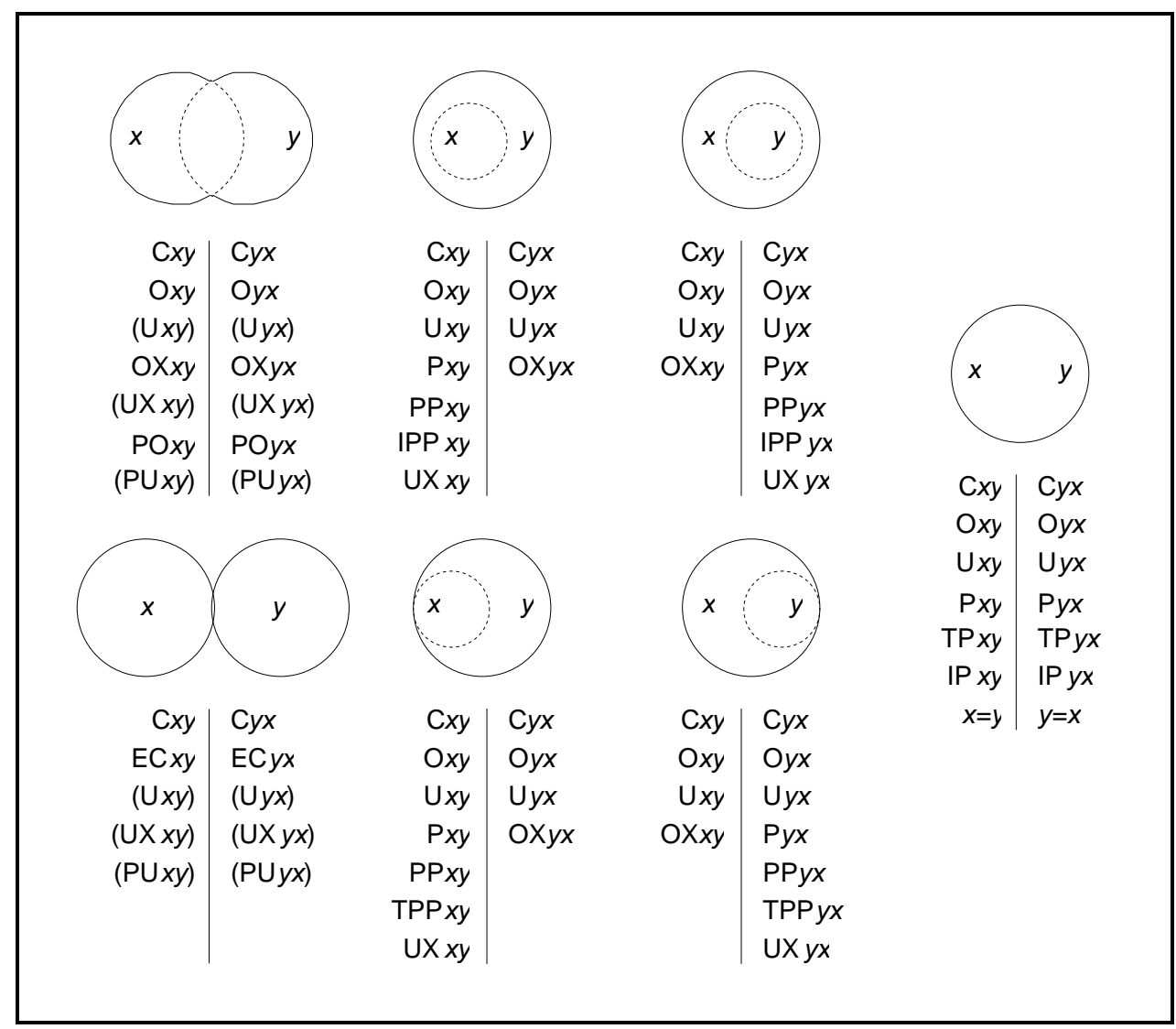

Figure 3: The seven basic patterns of the connection relationship.

Moreover, one can introduce further mereotopological relations along the following lines:
$\mathrm{E} x y \quad=_{\mathrm{df}} \forall z(\mathrm{C} z x \rightarrow \mathrm{C} z y)$
(38) IExy $=_{\mathrm{df}} \exists z(\mathrm{IP} z y \wedge \mathrm{E} x z)$
(39) TExy $=_{\mathrm{df}} \exists z(\mathrm{TP} z y \wedge \mathrm{E} x z)$
(40) $\mathrm{S} x y==_{\mathrm{df}} \exists z(\mathrm{E} z x \wedge \mathrm{E} z y)$
(41) $\quad \mathrm{SX} x y==_{\mathrm{df}} \mathrm{S} x y \wedge \neg \mathrm{E} x y$

(Enclosure)

(Internal Enclosure)

(Tangential Enclosure)

(Superposition)

(SuperCrossing) 


$$
\begin{aligned}
& \mathrm{PS} x y==_{\mathrm{df}} \mathrm{SX} x y \wedge \mathrm{SX} y x \quad \text { (Proper Superposition) } \\
& \mathrm{I} x y==_{\mathrm{df}} \mathrm{E} x y \wedge \mathrm{E} y x \quad \text { (Coincidence) } \\
& \text { (44) Axy }=_{\mathrm{df}} \mathrm{C} x y \wedge \neg \mathrm{S} x y \quad \text { (Abutting) }
\end{aligned}
$$

Unless the converse of (C3) is also assumed, these are all different from the relations of Figure 3 [71]. Intuitively, they correspond to the situations where the regions occupied by $x$ and $y$ stand in the corresponding Figure-3-relations obtained by replacing ' $\mathrm{E}$ ' with ' $\mathrm{P}$ ' throughout. (The relevant difference is captured by the relations defined by the scheme:

$$
\mathrm{D} R x y=_{\mathrm{df}} \mathcal{R} x y \wedge \neg \mathrm{O} x y
$$

('D' for 'Disjoint'), where $\mathcal{R}$ is any relation introduced in (37)-(43). Compare this with (34).) Of course, it is a matter of ontology whether there are any entities that can share (al least partially) the same region without sharing any parts. For instance, co-localization seems to be a sufficient condition for identity in the case of material objects. But other entities seem to evade the restriction. Two distinct events can be perfectly spatio-temporally co-located [20]. Or, to use a different terminology, events do not occupy the spatio-temporal region at which they are located [14], and can therefore share it with other things. The same is true of "immaterial entities" such as holes or shadows-if we accept them into our ontology [12].

One can also introduce various "limit" relations that exploit further the distinction between, say, interior and tangential parts. For instance, one can define boundary parts as those tangential parts that include no interior parts:

$$
\mathrm{BP} x y=_{\mathrm{df}} \quad \mathrm{TP} x y \wedge \neg \exists z(\mathrm{P} z x \wedge \mathrm{IP} z y)
$$

However, this and similar relations are somewhat more problematic. For one thing, their actual meaning in a model may vary considerably depending on the actual composition of the model's domain. (For instance, in a domain in which a sphere has only two proper parts, say, the right and left halves, each part counts as a boundary part of the sphere.) Secondly, various authors explicitly reject boundary elements. Along with the exact nature of the interaction between the two basic predicates ' $\mathrm{P}$ ' and ' $\mathrm{C}$ ', the existence of such elements is indeed a major source of disagreement among the various mereotopological systems put forward in the literature (see [74] for a critical discussion). The following sections will illustrate some alternative options. 
PARTS, WHOLES, AND PART-WHOLE RELATIONS

\section{COMBINING MEREOLOGY AND TOPOLOGY: THE FIRST STRATEGY}

Once the need for supplementing mereological notions with topological notions is recognized, there are essentially three main strategies one can pursue. The first is, in a sense, the obvious one, and is implicit in the exemplifications of the previous section: if topology cannot be made to fit merelogy, then we may just add it to a mereological basis. From this point of view, mereology can be seen as the ground theory on which theories of greater and greater complexity (including topology as well as, say, morphology or kinematics) can be built by supplying the necessary notions and principles. The second strategy is more radical and exploits the idea that mereology (as a theory of parthood) is indeed a subtheory of topology (theory of wholes). That is, if topology eludes the bounds of mereology, as Whitehead's dilemma illustrates, one may try and turn things around: start from topology right away and define mereological notions in terms of topological primitives. From this point of view, just as mereology can be seen as a generalisation of the even more fundamental theory of identity (parthood, overlapping, and even fusion subsuming singular identity as a definable special case), likewise topology could be viewed as a generalisation of mereology, where the relation of joining or connection takes over parthood and overlapping as special cases. Finally, we shall also consider a third strategy, which is a sort of vindication of mereology building on its formal generality: on this view, topology may after all be viewed a subtheory of mereology, viz. as a domainspecific subtheory, connection and kindred notions being accounted for in terms of part-relations among entities of a specified sort, e.g., spatial regions. (See [72] for more preliminary material on this taxonomy of strategies.) In this section we shall begin with some remarks on the first strategy.

The minimalistic account is straightforward from the foregoing remarks: we obtain a ground mereotopological theory of the first type simply by combining the "lexical" axioms of Ground Mereology with those of Ground Topology.

DEFINITION6. Ground Mereotopology is the theory $\mathbf{M T}$ defined by the $\mathbf{M}$-axioms (P1)-(P3) together with the $\mathbf{T}$-axioms (C1)-(C3).

(This set of axioms is actually redundant, and can be simplified by replacing (C2)-

(C3) with the single axiom

$$
\mathrm{P} x y \rightarrow \forall z(\mathrm{C} x z \rightarrow \mathrm{C} z y) .
$$


PARTS, WHOLES, AND PART-WHOLE RELATIONS

We keep (C1)-(C3) for greater perspicuity and ease of reference.) This is the theory presupposed by definitions (34) through (45), though it is hardly of any interest by itself. More generally, we may consider the result of adding $\mathbf{T}$ to stronger mereological bases than $\mathbf{M}$.

DEFINITION 7. Let $\mathbf{X}$ be any mereological theory. The Ground Mereotopology induced by $\mathbf{X}$ [labelled $\mathbf{X} \mathbf{T}$ ] is the extension of $\mathbf{X}$ obtained by adding the $\mathbf{T}$-axioms (C1)-(C3).

For example, a version of CEMT can be found in [12]. It distinguishes all defined relations of Section 3, and it supports a characterization of wholeness patterned after the customary topological definition, modulo a mereological rather than set-theoretical ordering: a self-connected whole is an object that cannot be split into two or more disconnected parts:

$$
\mathrm{SC} x=_{\mathrm{df}} \forall x \forall z(x=y+z \rightarrow \mathrm{C} y z) .
$$

That is: something $x$ is self-connected just in case one can go on a continuous path from any one part of $x$ to any other without ever leaving the $x$ itself. (Note that one could take ' $\mathrm{SC}$ ' as a primitive, and define ' $\mathrm{C}$ ' by the obvious emendment of Whitehead's definition for ' $\mathrm{J}$ ', as per the following equivalence:

$$
\text { CEMT }+\mathrm{C} x y \leftrightarrow \exists z(\mathrm{SC} z \wedge \mathrm{O} z x \wedge \mathrm{O} z y \wedge \forall w(\mathrm{P} w z \rightarrow \mathrm{O} w x \vee \mathrm{O} w y))
$$

See [14] for a suggestion along these lines.)

A more typical case is obtained by taking $\mathbf{X}=\mathbf{G E M}$. This theory has been considered for the first time in [30], and has been used by various authors in some form or another (see e.g. [71] for an explicit formulation). Using the full strength of the fusion axiom, in GEMT it is possible to integrate the quasi-Boolean mereological operators of sum, product, etc. with a variety of quasi-topological operators:

$$
\begin{aligned}
& \mathrm{i} x={ }_{\mathrm{df}} \sigma z \operatorname{IP} z x \quad \text { (interior) } \\
& \mathrm{e} x={ }_{\mathrm{df}} \mathrm{i}(\sim x) \quad \text { (exterior) } \\
& \mathrm{c} x=_{\mathrm{df}} \sim(\mathrm{e} x) \quad \text { (closure) } \\
& \mathrm{b} x=_{\mathrm{df}} \sim(\mathrm{i} x+\mathrm{e} x) \quad \text { (boundary) }
\end{aligned}
$$

(Like the operators in (15)-(17) and (21), these operators will be partially defined unless we assume the existence of a null individual (22).) These operators are rather well-behaved, and allow one to capture a number of important mereotopological no- 
tions. For instance, reference to the interiors makes it possible to refine the notion of wholeness introduced in (48). As it is, in fact, the predicate 'SC' is still too general to capture the desired notion of an integral whole-a one-piece entity. On the one hand, one needs a stronger notion of connectedness, ruling out entities made up of pieces that are connected only externally (in the sense of (34)), such as the sum of two balls barely touching each other. In GEMT, we may do so by requiring that also the entity's interior be self-connected:

$$
\operatorname{SSC} x={ }_{\mathrm{df}} \mathrm{SC} x \wedge \operatorname{SCi} x
$$

On the other hand, one needs some means for expressing the intuitive distinction between self-connected parts (such as the bottom half of a ball) and self-connected wholes (the entire ball). This can be done in GEMT by singling out those entities that are maximally strongly self-connected:

$$
\operatorname{MSSC} x=_{\mathrm{df}} x=\sigma y(\operatorname{P} x y \wedge \operatorname{SSC} y)
$$

or, more generally, by singling out entities that are maximally strongly self-connected relative to some property or condition $\phi$ :

$$
\phi-\operatorname{MSSC} x=_{\mathrm{df}} \phi[x] \wedge x=\sigma y(\mathrm{P} x y \wedge \phi[z] \wedge \mathrm{SSC} y) .
$$

These and similar facts make GEMT a mereotopological theory particularly interesting for the purpose of ontological investigations, although its topological structure is still very simple. The intended picture is given by the following [26].

PROPOSITION 2 (Grzegorczyk [30]). Let A be the class of non-empty regular elements of a Hausdorff topology, and define $x R y$ iff $x \cap \bar{y} \neq \varnothing$ for all $x, y \in A$. Then the structure $(A, \subseteq, R)$ is a model of $\mathbf{G E M T}$.

At this point, we can get closer to a standard topological structure in various ways by strengthening the set of relevant axioms as desired. For instance, let us introduce the usual distinction between open and closed individuals:

$$
\begin{aligned}
& \text { Opx }=_{\mathrm{df}} x=\mathrm{i} x \quad \text { (Open) } \\
& \mathrm{Cl} x=_{\mathrm{df}} x=\mathrm{c} x \quad \text { (Closed) }
\end{aligned}
$$

Then we obtain a structure corresponding the ordinary topological spaces (modulo a mereological rather than set-theoretical basis) by imposing (the analogues of) the usual closure conditions. 
PARTS, WHOLES, AND PART-WHOLE RELATIONS

DEFINITION 8. The theory of General Extensional Mereotopology with Closure conditions [GEMTC] is the extension of $\mathbf{G E M T}$ obtained by adding the following axioms:
(C4) $\quad \mathrm{Cl} x \wedge \mathrm{Cl} y \rightarrow \mathrm{Cl}(x+y)$
(C5) $\forall x(\phi \rightarrow \mathrm{Cl} x) \rightarrow(z=\pi x \phi \rightarrow \mathrm{Cl} z)$

or, equivalently,

$\left(\mathrm{C} 4{ }^{\prime}\right) \quad$ Op $x \wedge$ Opy $\rightarrow(z=x \times y \rightarrow \mathrm{Op} z)$

(C5') $\forall x(\phi \rightarrow \mathrm{Op} x) \rightarrow \mathrm{Op}(\sigma x \phi)$.

(In (C5) and (C4'), the consequent is in conditional form due to the lack of a null individual). The intuitive strength of this theory is illustrated by the following consequences, which correspond to (the mereologized version of) the standard $\mathrm{Ku}$ ratowski axioms for topological closure along with their analogues for the interior and boundary operators:

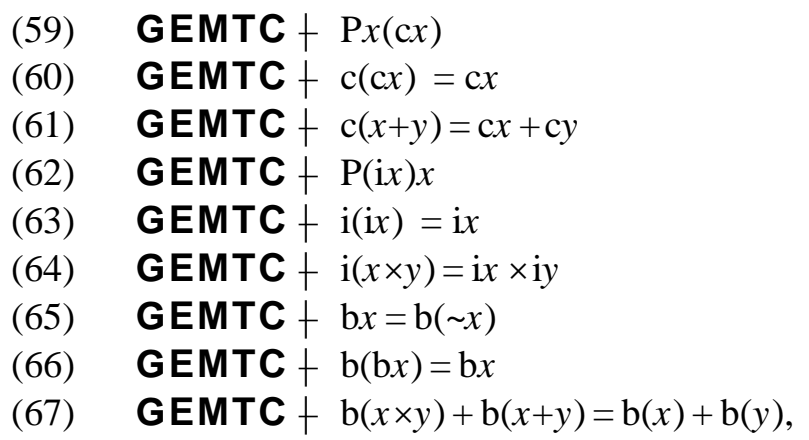

(These theorems are to be understood as holding whenever 'c', 'i', and 'b' are defined for the relevant arguments.) We also have the following, which show in what sense the interpretation of ' $C$ ' in GEMTC is germane to that of standard topology:

(68) GEMTC $+\mathrm{C} x y \leftrightarrow \mathrm{O} x(\mathrm{c} y) \vee \mathrm{O}(\mathrm{c} x) y$

(69) GEMTC $+\mathrm{EC} x y \leftrightarrow \mathrm{O} x(\mathrm{~b} y) \vee \mathrm{O}(\mathrm{b} x) y$

In view of properties such as these, GEMTC can be considered the archetype of a mereotopological theory based on the strategy under examination. Theories of this sort have been proposed by various authors, though often with a different choice of primitives and/or axiom sets. For instance, [65] gives a version of the theory using 'IP' as a primitive; $[48,49,50]$ give an equivalent formulation based on 'c' as a 
PARTS, WHOLES, AND PART-WHOLE RELATIONS

primitive and (60)-(61) as axioms. A version of the same theory based on the primitive 'boundary' is found in [51]. A slightly weaker formulation, based on 'IP', can also be found in [70], though this theory turns out to be defective in various respects. (In fact, it should be mentioned that the strategy of relying on the intuitive notion of an object being wholly within another goes as far back as [47]. Likewise, in the temporal realm, [36] outlines a Leś niewskian theory of time based on the relation of an interval being wholly earlier than another. The same approach underlies much linguistics-oriented work on time, tense, and aspect: see inter alia $[4,5,33,34,35,40]$.)

It is of course also possible to consider the hypothesis of combining topology with either atomistic or atomless mereologies. In particular, one may consider strengthening the assumption of mereological atomlessness with the requirement that everything have an interior proper part. This would give us a mereotopology in which there are no boundary elements.

DEFINITION 9. Let $\mathbf{X}$ be any Mereotopological theory. The Boundaryless variant of $\mathbf{X}$ [labelled $\overline{\mathbf{B}} \mathbf{X}$ ] is the extension of $\overline{\mathbf{A}} \mathbf{X}$ obtained by replacing (P10) with the axiom:

$$
\text { (C6) } \forall x \exists y \operatorname{IPP} y x \text {. }
$$

Obviously, $\mathbf{X}$ must not be atomistic, and $\overline{\mathbf{B}} \mathbf{X}$ can only have infinite models. Also, in view of (68)-(69), $\mathbf{X}$ must be weaker than GEMTC, on pain of inconsistency. More importantly, it is easily verified that $\overline{\mathbf{B}}$ GEMT will not be consistent unless we identify open and closed entities, for otherwise (C6) would contradict the supplementation axiom:

$$
\text { GEMT } \vdash \text { Op } x \wedge y=c x \rightarrow \neg \exists z \operatorname{IP} z(y-x) .
$$

So boundaryless theories are not easily accommodated within this framework. In fact, it should be stressed that most theories mentioned here (except [7]) are committed to the existence of boundary elements. (Some authors [30,33] have gone as far as construing boundaries as higher-order entities, in the spirit of the boundaryless theories discussed in the next section, but this is somewhat paradoxical if the theory allows for boundary individuals.) On the other hand, not much work has been done on the well-known intricacies stemming from the inclusion of such entities in the domain [74]. The issue is taken up in [63], where the point is made that a major feature of GEMTC lies precisely in the potential treatment of boundaries that it can 
PARTS, WHOLES, AND PART-WHOLE RELATIONS

deliver. In particular, the suggestion is made that GEMTC be further strengthened 
PARTS, WHOLES, AND PART-WHOLE RELATIONS

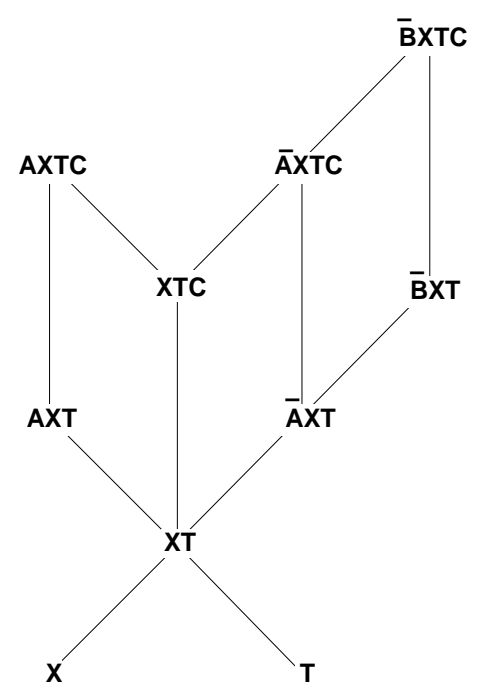

$\begin{array}{lllll}\text { (C1) } \quad \mathrm{C} x x & \mathbf{T} & \text { (C4) } & \mathrm{Cl} x \wedge \mathrm{Cl} y \rightarrow \mathrm{Cl}(x+y) & \text { XTC } \\ \text { (C2) } \mathrm{C} x y \rightarrow \mathrm{C} y x & \text { T } & \text { (C5) } & \forall x(\phi \rightarrow \mathrm{Cl} x) \rightarrow(z=\pi x \phi \rightarrow \mathrm{Cl} z) & \text { XTC } \\ \text { (C3) } \mathrm{P} x y \rightarrow \forall z(\mathrm{C} z x \rightarrow \mathrm{C} z y) & \mathbf{T} & \text { (C6) } \quad \forall x \exists y \mathrm{IPP} y x & \overline{\mathbf{B}} \text { XT }\end{array}$

Figure 4: Mereotopological theories of the first type induced by a mereological theory $\mathbf{X}$. (For perspicuity, it is assumed that $\mathbf{X}$ is neutral with respect to atomism; also, note that in the text the closure conditions defining $\mathbf{X T C}$ are given only for $\mathbf{X}=\mathbf{G E M}$ ).

by adding suitable principles reflecting e.g. the Aristotelian-Brentanian intuition that boundaries are parasitic entities, i.e., can only exist as boundaries of something (contrary to the set-theoretic conception of boundaries as ordinary independent entities). The formulation of such principles is in itself a rather difficult issue, as it would seem to involve an intricate interplay of mereotopological and modal notions. [65] suggests a minimal extensional formulation along the following lines

$$
\mathrm{B} x y \rightarrow \exists z \exists w(\mathrm{BP} x z \wedge \mathrm{IP} w z),
$$

where ' $\mathrm{B}$ ' is the boundary relation defined in the obvious way:

$$
\mathrm{B} x y==_{\mathrm{df}} \mathrm{P} x(\mathrm{~b} y) .
$$

We refer the reader to $[66,67,74]$ and to Smith's contribution to this issue for further developments of this suggestion. A different approach is indirectly suggested 
by the general strategy under examination, and consists in expanding the language by introducing a third distinguished predicate, say ' $\mathrm{D}$ ' for dependence. For instance, [25] suggests the following set of purely extensional axioms for ' $D$ ':

$$
\begin{aligned}
& \mathrm{P} x y \rightarrow \mathrm{D} y x \\
& \mathrm{D} x y \wedge \mathrm{D} y z \rightarrow \mathrm{D} x z \\
& \exists y(\mathrm{D} x y \wedge \forall z(\mathrm{D} x z \rightarrow \mathrm{P} z y)) .
\end{aligned}
$$

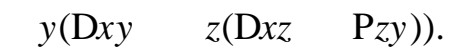

We can then address the dependent nature of boundaries by supplementing the theory with a specific principle relating the topological part to the theory of dependence:

$$
\mathrm{B} x y \rightarrow \mathrm{D} x y .
$$

Although more involved, such an account is very much in the spirit of the general strategy under examination (start with mereology, and then add topology and other theory fragments). Moreover, it can be extended to consider other relations of ontological dependency (e.g., the dependence of a hole on the surrounding object [12]). We see this as a rewarding subject for further exploration.

\section{SECOND STRATEGY: TOPOLOGY AS A BASIS FOR MEREOLOGY}

We consider now the second way to bridge the gap between merelogy and topology. As mentioned above, this strategy exploits the suggestion that topology is truly a more fundamental and more general framework subsuming mereology in its entirety, at least relative to certain domains. This view can be traced back to [21] and was eventually taken over by Whitehead himself in the final version of his theory in [79], where all notions are explained in terms of the ' $C$ ' predicate. In particular, definability of parthood is obtained by assuming also the converse of the basic mereotopological principle (C3) linking ' $\mathrm{P}$ ' to ' $\mathrm{C}$ '. This gives us the following basic characterization of this strategy.

DEFINITION 10. Strong Mereotopology [SMT] is the extension of MT obtained by adding the following axiom:

(C7) $\forall z(\mathrm{C} z x \rightarrow \mathrm{C} z y) \rightarrow \mathrm{P} x y$.

This, in turn, can be simplified by observing that (P1) and (P3) are now derivable from the other axioms. So in the end SMT is tantamount to the theory defined by (C1) and (C2) along with 
(P2') $\forall z(\mathrm{C} z x \leftrightarrow \mathrm{C} z y) \rightarrow x=y$,

which corresponds to (P2) with 'P' defined as indicated:

$$
\mathrm{P} x y={ }_{\mathrm{df}} \forall z(\mathrm{C} z x \rightarrow \mathrm{C} z y) .
$$

(This is actually the customary formulation of SMT found in the literature since [15].)

This scarcity of primitives and axioms is admittedly a major attractve feature of SMT, though one should not overestimate it. In fact, it is also possible to have a mereotopology of the first type based on a single primitive. For instance, in $[72,73]$ it is suggested to rely on the ternary relation " $x$ and $y$ are connected parts of $z$ ". Indicating this relation by ' $\mathrm{CP}$ ', one can easily define ' $\mathrm{P}$ ' and ' $\mathrm{C}$ ',

(78) $\quad$ P $x y==_{\mathrm{df}} \exists z \mathrm{CP} x z y$

(79) $\mathrm{C} x y==_{\mathrm{df}} \exists z \mathrm{CP} x y z$,

and then go on to develop a mereotopological theory of the first type based on the relative independence of these two predicates. (Note that (78) only presupposes connection to be reflexive, whereas (79) assumes every pair of connected entities to have a sum-two perfectly uncontroversial presuppositions.)

So the distinguishing feature of this second strategy is not its formal economy-its relying on a single primitive. It is, rather, conceptual economy: the notion of parthood is fully subsumed under the notion of connection, that is, in the end, under the notion of wholeness. And the theory of parthood is, strictly speaking, a subtheory of the theory of wholeness. On this approach, the limits of mereology are overcome by turning the problem upside down, as it were: topology can deliver the full story about parts and wholes.

There is some cost too, though. For an immediate consequence of (77) is the complete collapse of all the relations introduced in (37)-(43): enclosure becomes parthood, and everything else goes. With the notation of (45):

$$
\text { SMT }+\neg \mathrm{D} R x y \quad \text { for } \mathcal{R} \in\{\mathrm{E}, \mathrm{IE}, \mathrm{TE}, \mathrm{S}, \mathrm{SX}, \mathrm{PS}, \mathrm{I}\}
$$

This is straightforward if spatio-temporal regions are the only entities in the domain. If, however, mereotopology is to apply to real world objects and events (without identifying them with their spatio-temporal co-ordinates), then the reduction is more problematic. As we saw in the previous section, the possibility that things be co-located without there being any sharing of parts is in principle open, depending on the ontology admitted by the theory, and reasoning exclusively in terms of regions may 
therefore be inadequate for the general case. We can say that the mereotopology of things and events supervenes on that of their spatiotemporal regions. But then we need at least a theory of localization to account for the correspondence, and the initial advantage of doing without parthood as an independent concept seems lost. (See $[13,14,72]$ for a more detailed formulation of this point.)

We can of course generalize Definition 10 by considering strong extensions, not of $\mathbf{M T}$, but of richer mereotopological frameworks.

DEFINITION 11. Let $\mathbf{X}$ be any mereological theory. The Strong Mereotopology induced by $\mathbf{X}$ [labelled $\mathbf{S X T}$ ] is the extension of $\mathbf{X T}$ obtained by adding axiom (C7). The corresponding Strong Mereotopology with closure conditions [SXTC] is obtained by adding the closure axioms (C4)-(C5) (or, equivalently, $\left(C 4^{\prime}\right)-\left(C 5^{\prime}\right)$ ). The corresponding Boundaryless variant $[\overline{\mathbf{B}} \mathbf{S X T}(\mathbf{C})]$ is obtained by adding axiom (C6) (or by substituting it for (P9) or (P10), if one of these is part of $\mathbf{X})$.

This gives a better picture of the power of the reduction. It should be noted, however, that most (if not all) theories based on the exploitation of (C7) do not define the quasi-Boolean mereological operations in terms of ' $\mathrm{O}$ ' (eventually introduced via (3) with ' $P$ ' understood in terms of ' $C$ '). Rather, it is standard practice to make use of their C-based counterparts. In the presence of boundaries, this marks a relevant difference with respect to the ' + ' and '-' operators:

(15') $\quad x++^{\prime} y==_{\mathrm{df}} \quad 1 z \forall w(\mathrm{C} w z \leftrightarrow(\mathrm{C} w x \vee \mathrm{C} w y))$

(17') $\quad x--^{\prime} y==_{\mathrm{df}} \quad 1 z \forall w(\mathrm{P} w z \leftrightarrow(\mathrm{P} w x \wedge \neg \mathrm{C} w y))$.

For instance, if $x$ is closed and $y$ is the mereological complement of $x$, then $x+y=U$ but $x+{ }^{\prime} y=U-\mathrm{b} x$. Likewise, $U-x=\sim x$ but $U-' x=\sim x-\mathrm{b} x$. More generally, define the C-based operator of general sum (fusion) in this spirit:

$$
\sigma^{\prime} x \phi=_{\mathrm{df}} \mathrm{l} z \forall y(\mathrm{C} y z \leftrightarrow \exists x(\phi \wedge \mathrm{C} x y)) .
$$

Then all quasi-Boolean operators, and consequently all quasi-topological operators of the sort introduced in (50)-(53), are typically re-defined using (23') in place of (23). In the following, we shall use priming to indicate a theory exploiting such a way of proceding (so that, for instance, SCMT' will be the strong mereotopology induced by $\mathbf{C M}$ modulo a systematic replacement of $\sigma$ by $\sigma^{\prime}$ ). A thorough comparison of these theories with their mereology-based counterparts would be very useful, and represents an open issue in the literature. Here we confine ourselves to pointing out two important consequences of the fully topological approach based on (23'): 
PARTS, WHOLES, AND PART-WHOLE RELATIONS

$$
\begin{aligned}
& \text { SGMT' }+\neg \mathrm{C} x(\sim x) \\
& \text { SGMT' }+\neg \mathrm{SC} U
\end{aligned}
$$

Thus, if the universe is to be connected, one must either change the definition of complement, ' ', or the very notion of self-connectedness, 'SC' (or else work with a weaker theory in which the universe or the closure operators are not definable). We shall see that these are in fact the two main lines of development pursued by authors working from the perspective of this strategy. First, however, a couple of facts concerning the algebraic structure of the theories under consideration.

PROPOSITION 3a (Biacino \& Gerla [6]). Every model of SGMT' corresponds to a complete quasi-orthocomplemented lattice (= orthocomplemented lattice with the zero element removed) via the ordering induced by the definition of ' $P$ '.

PROPOSITION 3b (Asher \& Vieu [1]). $\overline{\mathbf{B}}$ SCMTC' is semantically consistent and complete (with respect to a well-defined class of quasi-orthocomplemented lattices of regular open subsets of a topological space).

We should also record that most theories developed in conformity with the strategy under examination (with the only apparent exception of [52]) are boundaryless. Whitehead [79], and after him Clarke [15,16] and various subsequent theories, explicitly suggested interpreting the individual variables as ranging over spatio-temporal regions, and ' $\mathrm{C}$ ' as the relation of sharing a common point. It is for this reason that their theory allows one to distinguish ' $\mathrm{C}$ ' from ' $\mathrm{O}$ '. Since points are not regions, connection does not imply overlapping, and regions may be externally connected. This marks an interesting difference from the boundary-based theories considered in the previous section: whereas in a theory such as GEMTC 'EC' is explained in terms of overlapping of a common boundary, as per (69), here the explanation is left open, for boundaries are simply not included in the domain. This difference, in turn, has at least one important consequence, namely the violation of the supplementation principle (P4) (even in its weak form (12)), and consequently of mereological extensionality. Although the systems under consideration have no room for boundaries, they do have room for the standard topological distinction between open and closed entities (definitions (57)-(58) still apply). But as we saw in (70), this distinction is inconsistent with the joint assumption of boundarylessness (C6) and mereological extensionality (P4). As a result, Proposition $3 \mathrm{~b}$ cannot 
PARTS, WHOLES, AND PART-WHOLE RELATIONS

be strengthened by extending $\overline{\mathbf{B}}$ SCMTC' to $\overline{\mathrm{B}}$ SCEMTC':

$$
\overline{\mathbf{B}} \mathbf{S C M T}(\mathbf{C})^{\prime}+\mathrm{Op} x \wedge y=\mathrm{c} x \rightarrow \neg \exists z(\mathrm{P} z y \wedge \neg \mathrm{O} z x) .
$$

Thus, an open region is always a proper part of its own closure, but there is no mereological difference between the two - a feature that some authors have found philosophically unpalatable $[60,74]$.

On the other hand, Asher \& Vieu's result [1] is in fact stronger that Proposition $3 \mathrm{~b}$, since the system which they prove to be consistent and complete is a proper extension of $\overline{\mathbf{B}} \mathbf{S} \mathbf{C M} \mathbf{T}^{\prime}$ obtained by adding $\left(\mathrm{C}^{\prime}\right)$ along with the following axioms:

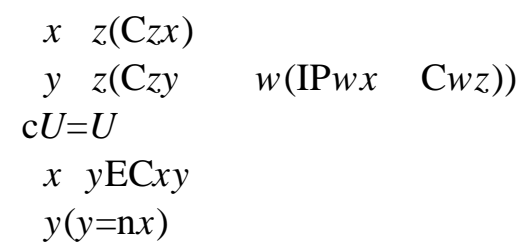

where ' $\mathrm{n}$ ' is the 'neighborhood' operator and 'WC' the relation of 'weak contact' corresponding to the case of two objects (regions) which, albeit disconnected, are 'vanishingly close' to each other:

$$
\begin{aligned}
& \mathrm{n} x==_{\mathrm{df}} \mathrm{l} y(\mathrm{P} x y \wedge \mathrm{Op} y \wedge \forall z(\mathrm{P} x z \wedge \mathrm{Op} z \rightarrow \mathrm{P} y z)) \\
& \mathrm{WC} x y==_{\mathrm{df}} \neg \mathrm{C} x y \wedge \mathrm{C} x(\mathrm{cn} y) .
\end{aligned}
$$

We shall call this system of $\overline{\mathbf{B}} \mathbf{S C M T W}$ ('W' for 'weak connection'). It is based on previous work by Vieu et al. [2,3,75] mostly motivated by applications to Natural Language Semantics, and may be taken as a representative of the second way of dealing with the tension arising from (81)-(82) above (disconnectedness of the universe). In this system, in fact, the notion of self-connectedness is suitably weakened:

$$
\text { (48') } \mathrm{SC} x=_{\mathrm{df}} \forall x \forall z(x=y+z \rightarrow \mathrm{C}(\mathrm{c} y)(\mathrm{c} z)) .
$$

The other way of dealing with the tension corresponds to the work of Cohn and his team $[18,52,54,55,56]$, which has come to be known as the RCC theory (Region Connection Calculus). This is simply a version of Clarke's theory (more precisely, a version of $\overline{\mathbf{B}} \mathbf{S} \mathbf{C M T}$ '-see [17, 28, 29] for further developments) motivated by a weaker interpretation of ' $\mathrm{C} x y$ ' as meaning 'the topological closures of regions $x$ and $y$ share a common point'. In a sense, the difference is only appar- 
ent: rather than changing the notion of ' $\mathrm{SC}$ ' by replacing the clause ' $\mathrm{Cyz}$ ' by ' $\mathrm{C}(\mathrm{c} y)(\mathrm{cz})$ ', RCC builds that change directly into the intended interpretation of the C-relation itself. However, this change carries along several significant consequences, making the departure more substantial than it would seem. In particular, this shift of interpretation is reflected formally in the abandonment of the quasiBoolean operation of complementation used in $\overline{\mathbf{B}}$ SCMTW' and in any system of the family $(\overline{\mathbf{B}}) \mathbf{S X T}(\mathbf{C})^{\prime}$ :

$$
\sim x==_{\text {df }} \operatorname{ly} \forall z(\mathrm{C} z y \leftrightarrow \neg \mathrm{P} z x)
$$

in favour of the following weaker variant:

$$
\sim x=_{\mathrm{df}} \operatorname{ly} \forall z((\mathrm{C} z y \leftrightarrow \neg \mathrm{IPP} z x) \wedge(\mathrm{O} z y \leftrightarrow \neg \mathrm{P} z x)) .
$$

This guarantees that every (non-universal) region be connected with its own complement, in contrast to (81):

$$
\text { RCC }+\mathrm{C} x(\sim x) .
$$

But (21") also has the effect of regaining the supplementation axiom (P4), which becomes provable:

$$
\mathbf{R C C} \vdash \neg \mathrm{P} x y \rightarrow \exists z(\mathrm{P} z x \wedge \neg \mathrm{O} z y) .
$$

So, $\mathbf{R C C}$ is an extension of EM. More generally, in RCC the distinction between open and closed regions collapses. This follows from the fact that ' $\mathrm{O}$ ' becomes an extensional relation:

$$
\mathbf{R C C}+\forall z(\mathrm{O} z x \leftrightarrow \mathrm{O} z y) \rightarrow x=y .
$$

Thus, it is not possible for two items to share exactly the same parts without having the same relationships in terms of connection, and in the presence of (C6) (the axiom that everything has interior parts) this deprives the open/closed distinction of any foundation. The authors motivate this change on intuitive grounds: if we map bodies to closed regions (the regions they occupy), then their complements become open, which means that if we allow bodies to break up into parts, one part will map to a closed region, and the other to a semi-open region-a result which the authors find counterintuitive (and which many other authors regard as a main motivation for going boundaryless in mereotopology). On the other hand, two consequences of this move should be recorded. First, RCC cannot be weakened by dropping the requirement of atomlessness. More precisely, we can drop the no-boundary axiom 
(C6), but reference to (21") does not support natural models with mereologically atomic regions. These would have the degenerate property that anything connected with them would also be connected with their complement, and by (C7) that would vacuously imply that every atomic region is part of its complement. (Some ways of dealing with this issue are discussed in [56].) Second, it follows that RCC cannot be extended to a general mereotopology supporting infinitary fusions. For in the presence of (93) and (94), the availability of the fusion axiom (P8') would yield the following theorem

$$
x=\mathrm{i} x=\mathrm{c} x .
$$

Since every region is connected with its complement, this would amount to saying that the fusion of the interior parts of any region is in contact with the complement of that region; likewise, since (the closure of) any region includes the fusion of the region's tangential parts, (95) says that by putting together the interior parts of any region, one eventually gets all of its tangential parts. Both consequences seem unacceptable. The only way to avoid them is therefore to prevent the definition of the ' $\mathrm{i}$ ' and 'c' operators.

In sum, the real distinguishing feature of $\mathbf{R} \mathbf{C} \mathbf{C}$ with respect to the systems of the family ( $\overline{\mathbf{B}}) \mathbf{S X T}(\mathbf{C})^{\prime}$ (and their $\mathbf{W}$-variants) is the position relative to the open/closed distinction-with all that goes with that. And the main distinguishing feature of all of these systems with respect to the systems discussed in the previous section (apart from the reduction of mereology to topology via (77)) is the position relative to the existence of boundary elements-with all that goes with that.

It should be added that the elimination of boundaries from the basic ontology of a $\overline{\mathbf{B}}$-theory does not rule out the possibility of providing at least an indirect account of such notions as "point", "line", and "surface" in such a way as to do justice to their customary geometrical properties. Following Whitehead's original work (but the idea goes back at least to Lobač evskij [41] and can also be found e.g. in $[44,69])$, this is typically done by construing boundary elements as higher-order entities. For instance, various accounts have been proposed treating points as sequences, sets, or even sets of sets of nested regions that "converge" (though not to an object proper). For a general overview of work in this area, we refer to [26] and [23] (but see also the treatment in [75]). This approach also has interesting analogues in the temporal realm, where instants are sometimes construed as sets of time intervals (which in turn are sometimes construed as sets of overlapping events). The locus classicus is Russell's construction in [59], which is echoed e.g. in 


\section{PARTS, WHOLES, AND PART-WHOLE RELATIONS}

$[76,33,5]$. 


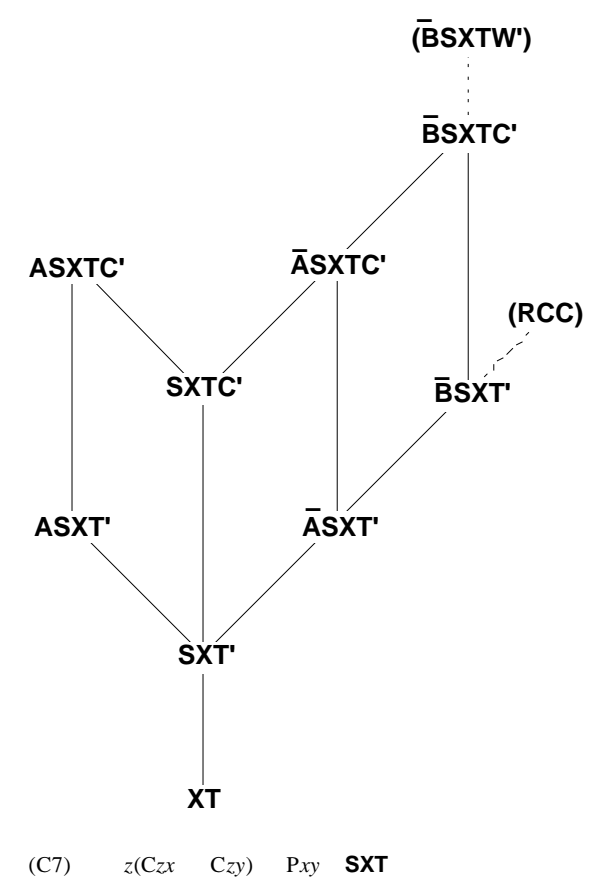

Figure 5: Basic mereotopological theories of the second type exploiting a mereological theory $\mathbf{X}$. In the text, $\mathbf{B}$ SXTW' is discussed only for $\mathbf{X}=\mathbf{C M}$; likewise, the positioning of $\mathbf{R} \mathbf{C C}$ holds for $\mathbf{X}=\mathbf{M}$. Note also that the mereological component $\mathbf{X}$ in a $\overline{\mathbf{B}} \mathbf{S X}$-theory cannot be extensional unless ' $\sim$ ' is defined as in $\mathbf{R C C}$.

\section{THIRD STRATEGY: TOPOLOGY AS A MEREOLOGY OF REGIONS}

We finally come to the third mereotopological strategy mentioned above, which has been put forward only recently [23,24]. Here the idea is that, in spite of "Whitehead's dilemma", a topological framework can be regained in a purely mereological setting (rather than vice versa) provided we embed it in a less restrictive domain. More precisely, one starts with a basic mereology and obtains topology as the restriction of mereology to the domain of regions (as opposed to points and other boundary-like elements). In this way, connection is neither more nor less than overlapping of regions, and yet the topological idea of external connection is made safe 
PARTS, WHOLES, AND PART-WHOLE RELATIONS

by the fact that the common part of two overlapping regions need not itself be a region. Using ' $R$ ' to indicate the new relevant (primitive) predicate of being a region, this leads to the following.

DEFINITION 12. Let $\mathbf{X}$ be any mereological theory. The Minimal Region-Based Mereotopology grounded on $\mathbf{X}$ [labelled $\mathbf{R B X}$ ] is the extension of $\mathbf{X}$ obtained by adding the following proper axioms for the Region predicate, ' $\mathrm{R}$ ':

(R1) $\quad \mathrm{C} x y \leftrightarrow \mathrm{O} x y \wedge \mathrm{R} x \wedge \mathrm{R} y$

(R2) $\quad \mathrm{EC} x y \leftrightarrow \mathrm{C} x y \wedge \forall z(\mathrm{P} z x \wedge \mathrm{P} z y \rightarrow \neg \mathrm{R} z)$.

(The treatment in $[23,24]$ focuses on the case $\mathbf{X}=\mathbf{G E M}$, but other options are open. Moreover, further specific axioms can be added to characterize the logic of ' $R$ '. For instance, [24] adds the closure axiom $(\mathrm{C} 4$ ') along with the following:

$$
\begin{aligned}
& \mathrm{R} x \rightarrow \exists y(\mathrm{Op} y \wedge \mathrm{P} x y) \\
& x=\sigma y(\mathrm{R} y \wedge \mathrm{P} y x) \rightarrow \mathrm{R} x,
\end{aligned}
$$

from which (C5') also follows. See also the axiomatic treatments of ' $R$ ' independently put forward in $[7,14]$.)

Of course, RBX can be formulated in a C-free language, using (R1) and (R2) as definitions. Thus, since one immediately verifies that all of (C1)-(C3) are already provable in the region-based theory grounded on Ground Mereology, RBM is nothing but $\mathbf{M}$, and topology is nothing but the subtheory that can be obtained by uniformly restricting the range of quantifiers by a monadic predicate, ' $R$ '. More precisely, let $L_{\mathrm{P}}$ be the language of pure mereology, $L_{\mathrm{C}}$ the language of strong mereotopology (with 'P' defined), and $L_{\mathrm{R}}$ the extension of $L_{\mathrm{P}}$ obtained by adding 'R'. Next, for any sentence $\phi_{\mathrm{P}}$ of $L_{\mathrm{P}}$, let $\phi_{\mathrm{C}}$ be the sentence of $L_{\mathrm{C}}$ obtained from $\phi$ by replacing each atomic component of the form 'P $x y$ ' with ' $\forall z(\mathrm{C} z x \rightarrow \mathrm{C} z y)$ ', and let $\phi_{\mathrm{R}}$ be the sentence of $L_{\mathrm{R}}$ obtained from $\phi_{\mathrm{P}}$ by recursively replacing each quantified component of the form ' $\forall x \psi$ ' or ' $\exists x \psi$ ' (with ' $x$ ' free in $\psi$ ) with ' $\forall x(\mathrm{R} x \rightarrow \psi$ )' and ' $\exists x(\mathrm{R} x \wedge \psi)$ ', respectively. Then we have the following general characterization.

PROPOSITION 4 (Eschenbach \& Heydrich [24], Varzi [72]). Let $\mathbf{K}_{\mathrm{P}}$ be a mereological theory in $L_{\mathrm{P}}$ and let $\mathbf{K}_{\mathrm{C}}$ and $\mathbf{K}_{\mathrm{R}}$ be corresponding theories in $L_{\mathrm{C}}$ and $L_{\mathrm{R}}$ obtained by replacing each $\mathbf{K}_{\mathrm{P}}$-axiom $\phi_{\mathrm{P}}$ with $\phi_{\mathrm{C}}$ or $\phi_{\mathrm{R}}$, respectively. Then, for every sentence $\phi_{\mathrm{P}}$ of $L_{\mathrm{P}}, \mathbf{K}_{\mathrm{R}}+\phi_{\mathrm{R}}$ iff $\mathbf{K}_{\mathrm{C}}+\phi_{\mathrm{C}}$. 
Thus, this approach allows one to keep within the boundaries of standard mereology while at the same time pursuing a perspective akin to that of a strong mereotopology. Some principles may not hold unrestrictedly in the restricted domain of regions; but this simply mirrors the fact that such a domain (the extension of the predicate ' $R$ ', on the intended interpretation) is deprived of some topologically relevant elements, points and boundaries in the first place. For example, set $\mathbf{K}_{\mathrm{P}}=\mathbf{M}$, so that $\mathbf{K}_{\mathrm{C}}=\mathbf{S} \mathbf{M} \mathbf{T}$ and $\mathbf{K}_{\mathrm{R}}=\mathbf{R B M}$. Then, taking $\phi_{\mathrm{P}}$ to be the supplementation axiom (P4), we have :

$$
\begin{aligned}
& \text { SEMT } H \neg \mathrm{P} x y \rightarrow \exists z(\mathrm{P} z x \wedge \neg \mathrm{O} z y) \\
& \text { RBEM } H \neg \mathrm{P} x y \rightarrow \exists z(\mathrm{R} z \wedge \mathrm{P} z x \wedge \neg \mathrm{O} z y),
\end{aligned}
$$

even though

$$
\begin{aligned}
& \mathbf{E M} \vdash \neg \mathrm{P} x y \rightarrow \exists z(\mathrm{P} z x \wedge \neg \mathrm{O} z y) \\
& \text { RBEM } \vdash \neg \mathrm{P} x y \rightarrow \exists z(\mathrm{P} z x \wedge \neg \mathrm{O} z y) .
\end{aligned}
$$

This shows that, in a sense, mereology needs very little help in order to cope with certain basic topological notions and principles. Formally it is only a matter of restricted quantification. If this amounts to saying that topology is exclusively about regions of space (or about whatever selected entities one employs to fill in the extension of ' $R$ '), then one might raise the same objections considered above in relation to the second strategy for combining mereology and topology: Whether we try to explain mereological relations among things in terms of topological relations among the corresponding regions (strong mereotopology), or topological relations among regions in terms of mereological relations among things of a kind (region-based mereotopology), we seem to miss out on something important for the mereotopological analysis of the everyday world. On the other hand, the present approach differs from that of the previous section in that it draws no necessary reduction of parthood to spatial connection, and this gives new content to the idea that topological reasoning about ordinary things can be inferred from the topology of the regions they occupy. On this approach, one may stick to reasoning about regions and yet keep track of the relevant difference between enclosure and parthood, or between superposition and overlapping. That is, the exact interplay between these notions is in principle left open. For this reason, further developments of this line of research-for instance in the spirit of a general theory of localization [14] — may deliver interesting results, casting new light on the fundamental patterns of interaction between mereology and topology. 


\section{PARTS, WHOLES, AND PART-WHOLE RELATIONS}

\section{REFERENCES}

[1] Asher N., Vieu L., 'Toward a Geometry of Common Sense: A Semantics and a Complete Axiomatization of Mereotopology', in Proceedings of the 14th International Joint Conference on Artificial Intelligence, Montreal: IJCAI [Morgan Kaufmann], to appear.

[2] Aurnague M., Vieu L., 1993a, 'A Three-Level Approach to the Semantics of Space', in C. Z. Wibbelt (ed.), The Semantics of Prepositions: From Mental Processing to Natural Language Processing, Berlin: Mouton de Gruyter, pp. 393-439.

[3] Aurnague M., Vieu L., 1993b, 'Toward a Formal Representation of Space in Language: A Commonsense Reasoning Approach', in F. Anger, H. Guesgen and J. van Benthem (eds.), Proceedings of the Workshop on Spatial and Temporal Reasoning. 13th International Joint Conference on Artificial Intelligence, Chambéry: IJCAI, pp. 123-58.

[4] Bach E., 1986, 'The Algebra of Events', Linguistics and Philosophy 9, 5-16.

[5] Benthem J. van, 1983, The Logic of Time, Dordrecht: Kluwer (2nd ed. 1991).

[6] Biacino L., Gerla G., 1991, 'Connection Structures', Notre Dame Journal of Formal Logic, 32, 242-47.

[7] Borgo S., Guarino N., Masolo C., 'A Naive Theory of Space and Matter', in P. Amsili, M. Borillo, and L. Vieu (eds.), Time, Space and Movement: Meaning and Knowledge in the Sensible World (Proceedings of the 5th International Workshop), Toulouse: COREP, 1995, pp. E29-32.

[8] Bostock D, 1979, Logic And Arithmetic, vol. 2:Rational and Irrational Numbers, Oxford: Clarendon Press

[9] Bunge M., 1966, 'On Null Individuals', Journal of Philosophy 63, 776-78.

[10] Bunge M., 1977, Treatise on Basic Philosophy, vol. 3: Ontology I: The Furniture of the World, Reidel: Dordrecht.

[11] Burkhardt H., Dufour C. A., 1991, 'Part/Whole I: History', in H. Burkhardt and B. Smith (eds.), Handbook of Metaphysics and Ontology, München: Philosophia, pp. 663-73.

[12] Casati R., Varzi A. C., 1994, Holes and Other Superficialities, Cambridge, MA, and London: MIT Press/Bradford Books.

[13] Casati R., Varzi A. C., 1995, 'Basic Issues in Spatial Representation', in M. De Glas and Z. Pawlak (eds.), Proceedings of the 2nd World Conference on the Fundamentals of Artificial Intelligence, Paris: Angkor, pp. 63-72.

[14] Casati R., Varzi A. C., 1996, 'The Structure of Spatial Localization', Philosophical Studies, to appear.

[15] Clarke B. L., 1981, 'A Calculus of Individuals Based on "Connection"', Notre Dame Journal of Formal Logic 22, 204-18.

[16] Clarke B. L., 1985, 'Individuals and Points', Notre Dame Journal of Formal Logic 26, 61-75.

[17] Cohn A. G., and Gotts N. M., 1994, 'The "Egg-Yolk" Representation of Regions with Indeterminate Boundaries", in C. Eschenbach, C. Habel and B. Smith (eds.), Topological Foundations of Cognitive Science. Papers from the Workshop at the First International Summer Institute in Cognitive Science, University of Hamburg, Reports of the Doctoral Program in Cognitive Science, No. 37, pp. 131-50. 


\section{PARTS, WHOLES, AND PART-WHOLE RELATIONS}

[18] Cohn A. G., Randell D. A., Cui Z., 1993, 'A Taxonomy of Logically Defined Qualitative Spatial Regions', in N. Guarino and R. Poli (eds.), International Workshop on Formal Ontology in Conceptual Analysis and Knowledge Representation, Padova: Ladseb-CNR, pp. 149-58.

[19] Cruse D. A., 1979, 'On the Transitivity of the Part-Whole Relation', Journal of Linguistics 15, 29-38.

[20] Davidson, D., 1969, 'The Individuation of Events', in N. Rescher (ed.), Essays in Honor of Carl G. Hempel, Dordrecht: Reidel, pp. 216-34.

[21] De Laguna T., 1922, 'Point, Line, and Surface, as Sets of Solids', Journal of Philosophy 19, 449-61.

[22] Eberle R. A., 1970, Nominalistic Systems, Dordrecht: Reidel.

[23] Eschenbach, C., 1994, 'A Mereotopological Definition of "Point", in C. Eschenbach, C. Habel, and B. Smith (eds.), op. cit., pp. 63-80.

[24] Eschenbach, C., and Heydrich, W., 1993, 'Classical Mereology and Restricted Domains', in N. Guarino and R. Poli (eds.), op. cit., pp. 205-17.

[25] Fine K., 1995, 'Part-Whole', in B. Smith and D. W. Smith (eds.), The Cambridge Companion to Husserl, New York: Cambridge University Press, pp. 463-85.

[26] Gerla G., 1995, 'Pointless Geometries', Chapter 18 of F. Buekenhout (ed.), Handbook of Incidence Geometry, Amsterdam: Elsevier, pp. 1015-31.

[27] Gerstl P, Pribbenow S., 1993, 'Midwinters, End Games, and Bodyparts. A Classifica tion of Part-Whole Relations', in N. Guarino and R. Poli (eds.), International Workshop on Formal Ontology in Conceptual Analysis and Knowledge Representation, Padova: Ladseb-CNR, pp. 251-60.

[28] Gotts, N. M., 1994a, 'How Far Can We 'C'? Defining a 'Doughnut' Using Connection Alone', in J. Doyle, E. Sandewall, and P. Torasso (eds.), Principles of Knowledge Representation and Reasoning: Proceedings of the Fourth International Conference, San Mateo, CA: Morgan Kaufmann, 1994, pp. 246-57.

[29] Gotts, N. M., 1994b, 'Defining a "Doughnut” Made Difficult', in C. Eschenbach, C. Habel, and B. Smith (eds.), Topological Foundations of Cognitive Science. Papers from the Workshop at the First International Summer Institute in Cognitive Science, University of Hamburg, Reports of the Doctoral Program in Cognitive Science, No. 37, pp. 105-29.

[30] Grzegorczyk A., 1960, 'Axiomatizability of Geometry Without Points', Synthese, 12, 10927.

[31] Henry D., 1991, Medieval Mereology, Amsterdam/Philadelphia: Grüner.

[32] Iris M. A., Litowitz B. E., Evens M., 1988, 'Problems of the Part-Whole Relation', in M. Evens (ed.), Relations Models of the Lexicon, Cambridge: Cambridge University Press, pp. 261-88.

[33] Kamp H., 1979, 'Events, Instants, and Temporal Reference', in R. Bäuerle, U. Egli and A. von Stechow (eds.), Semantics from Different Points of View, Berlin and Heidelberg: Springer-Verlag, pp. 376-417. 


\section{PARTS, WHOLES, AND PART-WHOLE RELATIONS}

[34] Krifka, M., 1989, 'Four Thousand Ships Passed Through the Lock: Object-Induced Measure Functions on Events', Linguistics and Philosophy, 13, 487-520.

[35] Landman F., 1991, Structures for Semantics, Dordrecht/Boston/London: Kluwer.

[36] Lejewski C., 1982, 'Ontology: What's Next?', in W. Leinfellner, E. Kraemer and J. Schank (eds.), Language and Ontology. Proceedings of the 6th International Wittgenstein Symposium, Vienna: Hölder-Pichler-Tempsky, pp. 173-85.

[37] Leonard H. S., Goodman N., 1940, 'The Calculus of Individuals and Its Uses', Journal of Symbolic Logic 5, 45-55.

[38] Leś niewski S., 1916, Podstawy ogólnej teoryi mnogoś ci. I, Moskow: Prace Polskiego Ko1 a Naukowego w Moskwie, Sekcya matematyczno-przyrodnicza (Eng. trans. by D. I. Barnett, 'Foundations of the General Theory of Sets. I', in S. Leś niewski, Collected Works, ed. S. J. Surma, J. Srzednicki, D. I. Barnett, F. V. Rickey, Dordrecht, Boston, and London: Nijhoff, 1992, Vol. 1, pp. 129-73).

[39] Lewis D. K., 1991, Parts of Classes, Oxford: Basil Blackwell.

[40] Link G., 1987, 'Algebraic Semantics for Event Structures', in J. Groenendijk, M. Stockhof and F. Veltman (eds.), Proceedings of the 6th Amsterdam Colloquium, Amsterdam: Institute for Language, Logic and Information, pp. 243-62.

[41] Lobač evskij N. I., 1834, 'Novye nač ala geometry s polnoj teoriej parallel'nyh' (New Principles of Geometry with Complete Theory of Parallels), Polnoe sobranie socinenij, 2, Moscow-Leningrad.

[42] Lowe V., 1953, 'Professor Goodman's Concept of an Individual', Philosophical Review 62, 117-26.

[43] Martin R. M., 1965, 'Of Time and the Null Individual', The Journal of Philosophy 62, 72336.

[44] Menger, K., 1940, 'Topology Without Points', Rice Institute Pamphlets 27, 80-107.

[45] Moltmann F., 1991, 'The Multidimensional Part Structure of Events', in A. L. Halpern (ed.), Proceedings of the Ninth West Coast Conference on Fornal Linguistics, Stanford: Center for the Study of Language and Information, pp. 361-78.

[46] Needham P., 1981, 'Temporal Intervals and Temporal Order', Logique et Analyse 24, 49-64.

[47] Nicod J., 1924, La geometrie dans le monde sensible, Paris: Alcan (Eng. trans. by J. Bell, 'Geometry in the Sensible World', in J. Nicod, Geometry and Induction, ed. R. F. Harrod, London: Routledge \& Kegan Paul, 1970, pp. 3-155).

[48] Pianesi F., Varzi A. C., 1994a, 'The Mereo-Topology of Event Structures', in P. Dekker and M. Stokhof (eds.), Proceedings of the 9th Amsterdam Colloquium, Amsterdam: Institute for Logic, Language and Computation, 1994, pp. 527-546.

[49] Pianesi F., Varzi A. C., 1994b, 'Mereotopological Construction of Time from Events', in A. G. Cohn (ed.), Proceedings of the 11th European Conference on Artificial Intelligence, Chichester: John Wiley \& Sons, pp. 396-400.

[50] Pianesi F., Varzi A. C., 1995, 'Refining Temporal Reference in Event Structures', to appear in Notre Dame Journal of Formal Logic (preliminary version in P. Amsili, M. Borillo, and L. Vieu (eds.), Time, Space and Movement: Meaning and Knowledge in the Sensible World (Proceedings of the 5th International Workshop), Toulouse: COREP, 1995, pp. D17-27). 


\section{PARTS, WHOLES, AND PART-WHOLE RELATIONS}

[51] Pianesi F., Varzi A. C., 1996, 'Events, Topology, and Temporal Relations', The Monist, 78/1 (1996), in press.

[52] Randell D. A., 1991, Analysing the Familiar: Reasoning about Space and Time in the Everyday World, University of Warwick: PhD Thesis.

[53] Randell D. A., Cohn A. G., 1989, 'Modelling Topological and Metrical Properties in Physical Processes', in R. J. Brachman, H. J. Levesque and R. Reiter (eds.), Principles of Knowledge Representation and Reasoning. Proceedings of the First International Conference, Los Altos: Morgan Kaufmann, pp. 357-68.

[54] Randell D. A., Cohn A. G., 1992, 'Exploiting Lattices in a Theory of Space and Time', Computers and Mathematics with Applications 23, 459-76.

[55] Randell D. A., Cui Z., Cohn A. G., 1992a, 'An Interval Logic of Space Based on "Connection"', in B. Neumann (ed.), Proceedings of the 10th European Conference on Artificial Intelligence, Chichester: John Wiley \& Sons, pp. 394-98.

[56] Randell D. A., Cui Z., Cohn A. G., 1992b, 'A Spatial Logic Based on Regions and Connection', in B. Nebel, C. Rich and W. Swartout (eds.), Principles of Knowledge Representation and Reasoning. Proceedings of the Third International Conference, Los Altos: Morgan Kaufmann, pp. 165-76.

[57] Rescher N., 1955, 'Axioms for the Part Relation', Philosophical Studies 6, 8-11.

[58] Russell B. A. W., 1905, 'On Denoting', Mind 14, 479-93.

[59] Russell B. A. W., 1914, Our Knowledge of the External World, London: Allen \& Unwin.

[60] Simons P. M., 1987, Parts. A Study in Ontology, Oxford: Clarendon Press.

[61] Simons P. M., 1991a, 'Part/Whole II: Mereology Since 1900', in H. Burkhardt and B. Smith (eds.), Handbook of Metaphysics and Ontology, München: Philosophia, pp. 209-10.

[62] Simons P. M., 1991b, 'Free Part-Whole Theory', in K. Lambert (ed.), Philosophical Applications of Free Logic, Oxford/New York: Oxford University Press, pp. 285-306.

[63] Smith B., 1982, 'Annotated Bibliography of Writings on Part-Whole Relations since Brentano', in B. Smith (ed.), Parts and Moments. Studies in Logic and Formal Ontology, München: Philosophia, pp. 481-552.

[64] Smith B., 1985, 'Addenda to: Annotated Bibliography of Writings on Part-Whole Relations since Brentano', in P. Sällström (ed.), An Inventory of Present Thinking about Parts and Wholes, vol. III, Stockholm: Forskningsrådsnämnden, pp. 74-86.

[65] Smith B., 1993, 'Ontology and the Logistic Analysis of Reality', in N. Guarino and R. Poli (eds.), International Workshop on Formal Ontology in Conceptual Analysis and Knowledge Representation, Padova: Ladseb-CNR, pp. 51-68.

[66] Smith B., 1995a, 'Zur Kognition räumlicher Grenzen: Eine mereotopologische Untersuchung', Kognitionswissenschaft, 4/4, 177-84.

[67] Smith B., 1995b, 'Boundaries', in L. Hahn (ed.), Roderick Chisholm, La Salle: Open Court, to appear.

[68] Tarski A., 1929, 'Les fondements de la géométrie des corps', Ksie ga Pamia tkowa Pierwszkego Polskiego Zjazdu Matematycznego, suppl. agli Annales de la Société Polonaise de Mathématique 7, 29-33. 


\section{PARTS, WHOLES, AND PART-WHOLE RELATIONS}

[69] Tarski A., 1935, 'Zur Grundlegung der Booleschen Algebra. I', Fundamenta Mathematicae, 24, 177-98.

[70] Tiles J. E., 1981, Things That Happen, Aberdeen: Aberdeen University Press.

[71] Varzi A. C., 1993, 'Spatial Reasoning in a Holey World', in P. Torasso (ed.), Advances in Artificial Intelligence. Proceedings of the 3rd Congress of the Italian Association for Artificial Intelligence, Berlin: Springer-Verlag, pp. 326-36.

[72] Varzi A. C., 1994a, 'On the Boundary Between Mereology and Topology', in R. Casati, B. Smith and G. White (eds.), Philosophy and the Cognitive Sciences, Vienna: Hölder-PichlerTempsky, pp. 419-38.

[73] Varzi A. C., 1994b, 'Things All of a Piece', in M. Somalvico (ed.), IV Convegno dell'Associazione Italiana per l'Intelligenza Artificiale: Atti del gruppo di lavoro "Aspetti Epistemologici e Gnoseologici dell'Intelligenza Artificiale”, Parma: Università degli Studi, pp. 55-58.

[74] Varzi A. C., 1995, 'Boundaries, Continuity, and Contact', in P. Amsili, M. Borillo, and L. Vieu (eds.), Time, Space and Movement: Meaning and Knowledge in the Sensible World (Proceedings of the 5th International Workshop), Toulouse: COREP, 1995, pp. D79-100.

[75] Vieu L., 1991, Sémantique des relations spatiales et inférences spatio-temporelles. Une contribution à l'étude des structures formelles de l'espace en Langage Naturel, Université Paul Sabatier de Toulouse: PhD Thesis.

[76] Walker A. G., 1947, 'Durées et instants', Revue Scientifique 85, 131-34.

[77] Whitehead A. N., 1919, An Enquiry Concerning the Principles of Human Knowledge, Cambridge: Cambridge University Press.

[78] Whitehead A. N., 1920, The Concept of Nature, Cambridge: Cambridge University Press.

[79] Whitehead A. N., 1929, Process and Reality. An Essay in Cosmologyy, New York: Macmillan.

[80] Winston M., Chaffin R., Herrmann D., 1987, 'A Taxonomy of Part-Whole Relations', Cognitive Science 11, 417-44. 